\title{
A Onda Rosa e o Neoliberalismo Resiliente
}

\author{
Moisés Balestro \\ Cristiano Fonseca Monteiro ${ }^{2}$
}

Os artigos contemplados neste número especial possuem várias chaves interpretativas para a persistência ou retomada do neoliberalismo na América Latina. Na primeira década do século XXI, houve um debate acadêmico e político sobre os contornos de um período pósneoliberal na região (eg. Diniz e Boschi, 2007; Boschi, 2011). A emergência do "pósneoliberalismo" teria sido alimentada pelo profundo desgaste político e social das reformas neoliberais dos anos noventa e pelo entusiasmo diante da ascensão de governos progressistas na América do Sul. Alguns destes governos, como nos casos do Brasil e Argentina, buscaram associar as políticas sociais e redistributivas com tentativas de construção de uma estratégia de desenvolvimento econômico. Em outras experiências, esta associação não ficou tão clara quanto nos casos do Equador, Bolívia e Venezuela. Nestes últimos, a ênfase maior ocorreu em torno do combate às desigualdades sociais e a ideia da soberania em torno das riquezas naturais existentes.

O período também foi conhecido como a "onda rosa" ("pink tide"), a qual logrou combinar, de forma ambivalente, o avanço de políticas sociais com combate a redução da pobreza e das desigualdades, sem a transformação das estruturas econômicas do capitalismo latino-americano. Os excedentes obtidos com o 'boom' das commodities permitiram financiar a expansão dos investimentos sociais. No caso dos países com maior mercado interno como Brasil e Argentina, houve iniciativas para fortalecer o tecido industrial que permitiram atender o aumento da demanda agregada. No entanto, embora esta fosse a intenção, o apoio do Estado para fortalecer a estrutura manufatureira não conseguiu avançar no catching-up e menos ainda transformar a estrutura industrial e social. A despeito da "retórica socialista" em alguns casos

\footnotetext{
${ }^{1}$ Professor Associado do Departamento de Estudos Latino-Americanos e do Programa de Pós-graduação em Estudos Comparados sobre as Américas moises@unb.br

2 Professor do Departamento de Sociologia e Metodologia das Ciências Sociais e do Programa de PósGraduação em Sociologia da Universidade Federal Fluminense. E-mail: cmonteiro@id.uff.br.
}

Revista de Estudos e Pesquisas sobre as Américas V.13 N.2 2019 ISSN: 1984-1639 
e da crítica aos legados históricos da escravidão, da dependência e do neoliberalismo, quais mudanças institucionais no capitalismo latino-americano com a "onda rosa"?

Ao analisar a dependência do capitalismo latino-americano, Florestan Fernandes (1975) chama atenção ao dilema das estruturas econômicas e sociais capazes de absorver a transformações do capitalismo na economia, mas sem lograr a integração social e a autonomia ocorridas no desenvolvimento capitalista dos países centrais - poderíamos acrescentar, ou mesmo mais recentemente no Leste asiático. Por outro lado, a dominação externa que estimulou a modernização capitalista desde fora bloqueia o desenvolvimento autônomo. Assim, quando se considera a longue durée do desenvolvimento capitalista, o aumento da desigualdade e da regressão produtiva aprofundado pelo neoliberalismo não é algo estranho à trajetória destes países. Apesar absorção da dinâmica capitalista com os processos de industrialização, ela se deu mais reforçando do que alterando as estruturas endógenas destas sociedades (Fernandes, 1975).

As experiências da "onda rosa" não questionaram o capitalismo propriamente dito, mas apontavam reformas que poderiam conduzir a mudanças institucionais nestes capitalismos. Foram políticas públicas mais ou menos articuladas para redução da pobreza, revitalização industrial e estímulo ao desenvolvimento tecnológico e ampliação da cidadania social. A crise de 2007-2008 teve um efeito contraditório sobre as experiências dos governos progressistas na AL. De um lado, ela contribuiu para as críticas que já eram feitas ao neoliberalismo por estes governos em maior ou menor grau. A crise parecia ter minado definitivamente a legitimidade do ideário neoliberal na sociedade e mesmo entre os partidos políticos. No entanto, como aponta Springer (2018), quase dez anos depois da crise de 2008, parece que se está testemunhando a emergência de uma forma nova e consolidada de neoliberalismo. De uma perspectiva a partir dos países desenvolvidos, autores como Crouch (2011) e Dardot e Laval (2016) também corroboram a continuidade e resiliência do neoliberalismo.

Com o retorno dos governos neoliberais na Argentina, no Chile e no Brasil, fica claro que o ideário e as propostas deste matiz não possuem a viabilidade e legitimidade política a elas conferidas na década de 1990 no tripé democratização, modernização e reformas de mercado. No entanto, seria um equívoco subestimar o poder remanescente e ainda dominante do neoliberalismo (Springer, 2018). 
A crise de 2007-2008 que afetou duramente o ciclo de boom das commodities também colocou o conflito distributivo na ordem do dia. Com a queda dos excedentes das exportações de commodities valorizadas, a macroeconomia baseada na poupança externa com câmbio valorizado e taxas de juros elevadas não podia mais coexistir com a expansão dos gastos sociais e aumento real do salário mínimo.

Embora tenha sido algo mais proeminente na experiência de governos progressistas no Brasil, postergar os conflitos distributivos com as elites agrárias e rentistas enfraqueceu a possibilidade da construção de uma coalizão entre classes duradoura como tem apontado análises recentes de Bresser-Pereira (eg. Bresser-Pereira, 2018). Além disso, é parte da natureza da experiência social-democrata o enfrentamento do conflito distributivo (Przeworski, 2012). Por outro lado, há dificuldades estruturais para as classes trabalhadoras latino-americanas formarem um bloco sociopolítico coeso em função das diferenças marcantes entre trabalho formal e informal, trabalho qualificado e trabalho não-qualificado, trabalhadores do serviço público e trabalhadores do setor privado (Roberts, 2008).

A heterogeneidade estrutural dos países latino-americanos implica uma diversidade na própria conformação das estratégias de desenvolvimento em curso em na região. Com a vantagem de um olhar retrospectivo, hoje é possível afirmar que as abordagens que se organizaram em torno do "pós-neoliberalismo" pareceram dar pouco espaço para esta diversidade, para não falar nas contradições existentes nas estratégias de desenvolvimento propriamente ditas dentro de cada país. Assim, mesmo argumentos voltados à centralidade da dimensão política tenderam a enxergar a "onda rosa" muito mais voltada à perspectiva da ruptura com o neoliberalismo que havia caracterizado a década anterior, do que com suas possíveis contradições, eventualmente tentando avançar na definição de um novo modelo de desenvolvimento, o "neodesenvolvimentismo".

O presente volume é um esforço no sentido de realizar uma reflexão crítica sobre esta trajetória, tentando explorar suas contradições e legados. Abrangendo diferentes temas da economia política, os artigos que compõem o dossiê exploram as nuances e ambiguidades destas experiências para entender em que medida o continente passa por uma retomada ou se trata de uma continuidade do neoliberalismo que agora se revela mais claramente hostil e limitado para absorver as pressões sociais. Afinal, foi uma década de ruptura ou de continuidade em relação à trajetória de liberalização em um sentido mais amplo da economia e da vida social?

Revista de Estudos e Pesquisas sobre as Américas V.13 N.2 2019 ISSN: 1984-1639 
Os artigos reunidos neste volume respondem esta questão de diferentes perspectivas, oferecendo ao leitor um panorama que no seu conjunto é crítico em relação ao significado da “onda rosa" como parte da história do capitalismo na América Latina. É justamente de uma perspectiva histórica de mais largo prazo que alguns dos artigos analisam esta experiência, enfatizando suas limitações estruturais, próprias de um capitalismo periférico.

É o caso do artigo de Jales da Costa e Wolney de Carvalho, que discute o neoliberalismo na América Latina como "ratificação do capitalismo dependente", suas implicações para a classe trabalhadora e as limitadas conquistas dos governos de esquerda na região diante do quadro de dependência. Além das limitações do desenvolvimento industrial associadas às políticas macroeconômicas com câmbio sobrevalorizado, com altas taxas de juros e elevada dependência da poupança externa, o artigo chama atenção para identificação ideológica entre as burguesias latino-americanas e o neoliberalismo. $\mathrm{O}$ autor destaca que o nacionalismo econômico e político não fazem mais parte do ideário das elites econômicas da América Latina.

O texto de Luis Fernando Garzon, por sua vez, inspira-se na tradição gramcsiana, no neoinstitucionalismo e no neomarxismo para devassar um alongado ciclo de rupturas e permanências econômicas e políticas no Brasil a partir de 1994. O autor fala de "ressurgências neoliberais" como consequência do insucesso de alternativas almejáveis e palpáveis que teriam sido sistematicamente sabotadas e neutralizadas - é o caso das mobilizações da década de 1980, sucedidas pelas políticas neoliberais da década seguinte. Nesta trajetória, os governos do Partido dos Trabalhadores teriam servido como "freio de arrumação" político e social, para a adoção de um "neoliberalismo inclusivo", cujo limite estaria em um "reformismo incremental" limitado pelos interesses do capital. Com o que o autor chama de "ruptura institucional de 2016", tem-se um cenário marcado pela "revanche do valor", no qual a agenda neoliberal avança, como uma "terceira onda de mercadorização" à la Polanyi, sem indícios de uma nova grande transformação à vista.

Ainda nesta perspectiva histórica e mais estrutural, Ricardo Rebello explora o plano das ideias e das comunidades epistêmicas, destacando o papel das organizações internacionais como BID e Banco Mundial na disseminação da episteme da governança global. O caráter normativo-prescritivo das soluções construídas, traduzidas e sistematizadas pelos organismos internacionais constitui uma espécie de "camisa de força” da governança global que foi também pervasiva durante os governos progressistas. Em conclusão, o autor questiona se o 
"novo desenvolvimentismo", que animou os governos da "onda rosa", não seria mais que um rearranjo (falacioso) da produção de conhecimento hegemônico, contribuindo para a cooptação de atores nacionais para os interesses dos grandes capitais financeiros internacionais.

Uma outra forma de aproximação ao neoliberalismo aparece em um conjunto de artigos mais preocupados com as especificidades nacionais, escrutinando em mais detalhes os desafios enfrentados por alguns países da região no período. $\mathrm{O}$ trabalho de Bruna dela Torre, Eduardo Altheman e Vladimir Puzone se debruça sobre o caso brasileiro, revelando os "desdobramentos neoliberais do Lulismo". Com base na pesquisa empírica realizada pela Fundação Perseu Abramo logo após a vitória de João Dória na cidade de São Paulo em 2016, os autores exploram as mudanças culturais ocorridas na periferia da maior cidade brasileira, revelando o alinhamento da população com valores liberais, tais como o empreendedorismo, sucesso pessoal e, no polo negativo, a crítica ao Estado. Este cenário seria consistente com um conjunto de políticas públicas promovidas pelos governos petistas que teriam contribuído, na interpretação dos autores, para o "conformismo da subjetividade da classe trabalhadora com a ideologia neoliberal".

O caso chileno é explorado por Aldo Madariaga, que propõe uma "abordagem holista", compreendendo uma análise das ideias, das instituições e dos interesses que conformaram o caso chileno, explicando a permanência do neoliberalismo construído a partir da ditadura de Augusto Pinochet, atravessando diversos ciclos políticos, incluindo governos de esquerda. $\mathrm{O}$ autor destaca a importância dos atores de veto alinhados com a defesa do neoliberalismo e contrários às reformas progressistas. Os atores de veto incluíram os tribunais constitucionais nos quais os atores de veto possuíam maioria, mesmo quando não estivessem no parlamento, além do enorme poder intelectual do pensamento neoliberal dentro das universidades que ganham espaço decisivo nos debates públicos, contando ainda com a influência nos meios de comunicação. Indo além do caso chileno, o autor considera que esta abordagem pode contribuir para entender a dinâmica e continuidade do neoliberalismo em países como o México, a Colômbia e o Peru.

Os artigos de Pedro Henrique Cícero e Ana Victória Diogo e de Danila Aguiar e Janaína Santos, por sua vez, abordam o caso da Bolívia, que chama atenção pela tentativa de construção de um "Estado plurinacional", visando romper não só com o modelo econômico neoliberal, mas com o próprio modelo político do Estado-nação. Cícero e Diogo constroem a 
análise a partir do conceito de "Estado abigarrado", entendido como um Estado que é resultado de uma mal articulada sobreposição de tempos históricos, modos de produção, línguas e visões de mundo, o que torna o modelo clássico de Estado-nação inadequado para se pensar a realidade latino-americana. A partir da análise da trajetória política do MAS, movimento político liderado pelo presidente Evo Morales, chega-se aos limites encontrados pelo movimento, que segue comprometido com uma visão neodesenvolvimentista, portanto ainda presa ao modelo de Estado tradicional cuja crítica estava na origem do movimento. Aguiar e Santos também reconstroem a mesma trajetória, lançando mão de uma perspectiva dos "blocos no poder", argumentando que o MAS estabeleceu uma hegemonia política baseada em alianças que envolveram frações burguesas estatais, demandas de perfil nacionalpopular e indígenas. Contudo, trata-se de um bloco neodesenvolvimentista que continua favorável ao capital estrangeiro.

Por fim, há um terceiro grupo de trabalhos que procura pensar o papel de agentes específicos na conformação da trajetória do neoliberalismo na América Latina. De um lado, Dieter Plehwe e Karin Fischer exploram o papel desempenhado pelos think tanks no enraizamento do ideário neoliberal na região. Os autores são enfáticos ao chamar atenção para uma análise mais profunda das dimensões socioeconômicas e ideológicas da distribuição de poder nas sociedades capitalistas. A "onda rosa" falhou em confrontar e minar as variedades neoliberais de capitalismo na América Latina assentada em tais dimensões. Por outro lado, as reformas institucionais resultaram mais das oportunidades criadas pela conjuntura internacional do que resultado de um esforço sistemático, o que limitou as possibilidades de transformação.

Sandro Garcia, por sua vez, aborda as limitações das políticas de apoio à inovação, destaca o elo fraco desta atividade no Brasil no período de 2004 a 2014. O período que coincide com as principais políticas industriais mostra a expansão dos gastos governamentais em inovação e com expansão da produção de conhecimento científico sem uma correspondência nos investimentos empresariais. Segundo o autor, a insuficiência de mecanismos de reciprocidade e de cooperação entre atores do setor público e privado estaria por trás da dificuldade em alcançar a transformação destes gastos em maiores taxas de inovação.

Fechando o dossiê, o artigo de Rodrigo Santos lança um olhar sobre a firma como instituição chave do capitalismo, analisando a forma como o ideário neoliberal do 
fundamentalismo de mercado constitui a governança corporativa (GC). O autor analisa a mudança institucional em direção a um modelo neoliberal de GC a partir do caso da Vale S.A, chamando atenção para o processo essencialmente político da redistribuição do poder e das condições de exercício do controle da firma em favor dos proprietários ou da lógica institucional do mercado em detrimento da lógica profissional e das estruturas de regulação. No plano ideológico, a mudança institucional implicou um maior alinhamento com os modelos de governança corporativa anglo-saxônica calcada na chamada ideologia de maximização do valor ao acionista (shareholder value maximizing ideology).

Em sentido teórico mais amplo, os artigos deste número especial mostram a necessidade de um escrutínio maior das características do capitalismo enquanto sociedade e economia. Como lembra Streeck (2016), uma sociedade capitalista se caracteriza pela conexão e interação entre relações sociais de produção e de intercâmbio com relações sociais não-econômicas. No caso do neoliberalismo, é preciso uma virada na ênfase do estudo do governo e dos partidos para uma ênfase na sociedade. É essencial entender o imbricamento social e ideológico deste ideário na reprodução social da vida cotidiana. Parte dos fracassos políticos e eleitorais dos governos progressistas se deve ao alcance societal do neoliberalismo.

Por outro lado, as ilusões que caracterizam o fundamentalismo de mercado (Block, 2018) também comprometem a sua legitimidade política e social. A ilusão de que a única forma possível de funcionamento da economia capitalista é a neoliberal. A ilusão de que não existe alternativa porque a própria definição de capitalismo implica mercados autônomos e auto-regulados. E, mais recentemente, a ilusão de que a democracia é crescentemente um empecilho para o funcionamento eficiente da economia.

É muito difícil antever os desdobramentos da retomada da ofensiva neoliberal na América Latina, mas é possível asseverar que a falta de legitimidade e a crescente coerção em detrimento da hegemonia revelam uma elevada instabilidade política e problemas de legitimidade mais agudos do que em sua fase áurea dos anos 90. Diante deste quadro, o presente número especial é também um convite para que os cientistas sociais renovem o interesse pela temática. Boa leitura!

\section{Referências}

Revista de Estudos e Pesquisas sobre as Américas V.13 N.2 2019 ISSN: 1984-1639 
BLOCK, Fred. Capitalism: the future of an illusion. Oakland, University of California Press, 2018.

BOSCHI, Renato. Variedades de capitalismo, política e desenvolvimento na América Latina. Belo Horizonte, UFMG, 2011.

BRESSER-PEREIRA, Luis Carlos. Direitos republicanos e a captura 'legal' do Estado brasileiro. Revista do Serviço Público, n. 69, pp. 15-30, 2018.

CROUCH, Colin. The Strange Non-Death of Neoliberalism. Cambridge, Polity Press, 2011.

DARDOT, Pierre; LAVAL, Christian. A nova razão do mundo: ensaios sobre a sociedade neoliberal. São Paulo, Boitempo, 2016.

DINIZ, Eli ; BOSCHI, Renato. A difícil rota do desenvolvimento: empresários e a agenda pós-neoliberal. Belo Horizonte, UFMG, 2007.

FERNANDES, Florestan . Capitalismo dependente e classes sociais na América Latina. Rio de Janeiro, Editora Zahar, 1975.

ROBERTS, Kenneth, Es posible una Socialdemocracia en América Latina ? Nueva Sociedad, n. 217, pp. 86-98, 2008.

PRZEWORSKI, Adam. Social Democracy as a Historical Phenomenon. In Capitalism and social democracy. Cambridge, Cambridge University Press, 2012.

SPRINGER, Simon. No More Room in Hell: Neoliberalism as Living Dead. In CAHILL, D., COOPER, M., KONINGS, M., PRIMOROSE, D., The SAGE Handbook of Neoliberalism, London, Sage Publications, 2018.

STREECK, Wolfgang. How will capitalism end? London, Verso, 2016. 